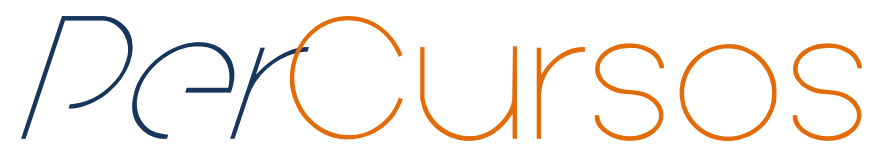

\title{
Ensino superior, PIBID e formação continuada na educação básica: primeiras aproximações
}

\section{Resumo}

O estudo investigou o Ensino Superior e o PIBID na formação continuada na Educação Básica, bem como questões relacionadas aos estudantes que participam do PIBID em sua formação inicial. O programa insere-se no contexto das políticas públicas de formação docente, possibilita a articulação entre os conhecimentos teóricos e a prática pedagógica. A pesquisa qualitativa, de cunho exploratório na metodologia de análise de conteúdo envolveu cinco professores supervisores; cinco acadêmicos bolsistas; e três coordenadores de área. Os autores principais que fundamentam este estudo foram Candau (2011), Nóvoa (2009), Tardif e Lessard (2008) no que concerne à necessidade da articulação entre teoria e prática, bem como Ferreira (2007) e Zabalza (2004), reforçando a importância da formação continuada docente. A coleta efetuada a partir de entrevistas semiestruturadas evidenciou que $O$ PIBID possibilita a aproximação das discussões acadêmicas com as práticas realizadas no contexto escolar. Os envolvidos destacaram a oportunidade de compreender e aprender o exercício da profissão nas relações entre teoria e prática; planejamento e execução das ações pedagógicas; nas reflexões sobre a própria prática e na importância dos espaços coletivos de convivência acadêmica e profissional. O programa rompe paradigmas ultrapassados de formação que valorizam somente a prática ou apenas a teoria. Na percepção dos acadêmicos, foi oportunizada a compreensão do fazer docente, processo complexo que necessita ser percebido como exercício permanente de análise, estudo e reflexão. É necessário aprofundar as questões das práticas exercidas na Educação Superior com vistas à formação docente nos Cursos de Licenciatura e repensar os programas de formação continuada.

Palavras-chave: Educação Superior. Programa de Iniciação à Docência-PIBID. Formação Continuada. Educação Básica.

\author{
Ortenila Sopelsa \\ Doutora em Educação pela \\ Universidade Metodista de \\ Piracicaba - UNIMEP. Professora \\ da Universidade do Oeste de \\ Santa Catarina - UNOESC. \\ Brasil \\ ortenila.sopelsa@unoesc.edu.br
}

\section{Regina Oneda Mello}

Mestre em Educação pela Universidade do Oeste de Santa Catarina - UNOESC. Professora da Universidade do Oeste de Santa Catarina - UNOESC. Brasil

regina.mello@unoesc.edu.br

\section{Para citar este artigo:}

SOPELSA, Ortenila; MELLO, Regina Oneda. Ensino superior, PIBID e formação continuada na educação básica: primeiras aproximações. Revista PerCursos, Florianópolis, v. 18, n.36, p. 277 - 299, jan./abr. 2017. 


\title{
Higher education, PIBID and continuing education in basic education: first approximations
}

\begin{abstract}
The study investigated Higher Education and PIBID in continuing education in Basic Education, as well as issues related to students who participate in PIBID in their initial formation. The program is part of the public policies of teacher training, it allows the articulation between theoretical knowledge and pedagogical practice. The qualitative research, of exploratory nature in the content analysis methodology involved five supervisors; Five academic scholars; Three area coordinators. The main authors of this study were Candau (2011), Nóvoa (2009), Tardif and Lessard (2008) regarding the need to articulate theory and practice, as well as Ferreira (2007) and Zabalza (2004). Importance of continuing teacher education. The collection made from semi-structured interviews showed that the PIBID allows the approximation of the academic discussions with the practices carried out in the school context. Those involved highlighted the opportunity to understand and learn the practice of the profession in the relations between theory and practice; Planning and execution of pedagogical actions; Reflecting on the practice itself and on the importance of collective spaces for academic and professional coexistence. The program breaks down outdated training paradigms that value only practice or just theory. In the perception of the academics, it was opportunized the understanding of the teaching profession, a complex process that needs to be perceived as a permanent exercise of analysis, study and reflection. It is necessary to deepen the questions of practices carried out in Higher Education with a view to teacher training in the Degree Programs and rethinking the programs of continuing education.
\end{abstract}

Keywords: College Education. PIBID. Continuing Education. Basic Education. 


\section{Introdução}

A exigência de professores cada vez mais qualificados, aptos a intervirem de forma efetiva nas mais diversas situações da sala de aula, é uma urgência social. É nesse contexto que o Ensino Superior se constitui no mais elevado nível da educação brasileira, uma vez que tem a responsabilidade de formar os formadores educacionais do país. De acordo com a Lei de Diretrizes e Bases da Educação Nacional, cabe a esse nível de ensino fomentar "a criação cultural e o desenvolvimento do espírito científico e do pensamento reflexivo" (BRASIL, 1996).

Na universidade, o ensino é um processo de busca, de construção científica e crítica ao conhecimento produzido, ou seja, de fomentar o conhecimento na construção da sociedade. Isso implica considerar que a educação, na qualidade de ação necessária à formação do ser humano, não é apenas um meio de adaptação ao presente, mas objetiva o desenvolvimento integral do ser humano à projeção de um futuro melhor para a humanidade.

Em razão disso, a formação de professores emerge com grande força nas discussões referentes à educação. A importância da formação deriva da necessária vinculação ao crescimento e aperfeiçoamento que tem de ser entendido em sentido global. Que saberes devem ser priorizados? As diferentes transformações da contemporaneidade em todos os aspectos da vida cotidiana vêm exigindo da educação um repensar constante e contínuo dos Cursos de Formação e das práticas educativas.

Para Zabalza (2004, p. 38), “discutir 'formação’ não costuma ser algo habitual nos estudos pedagógicos. A formação de professor tem apontado para a necessidade de encaminhamentos de propostas, programas, cursos e projetos de formação continuada". Entende-se que educação é processo contínuo, não acaba com a formação inicial, mas é constante busca de aperfeiçoamento por meio de inúmeras alternativas para o desenvolvimento do conhecimento aprimorado, seja teórico, epistemológico e/ou prático do saber.

Os projetos do Programa Institucional de Bolsa de Iniciação à Docência (PIBID) são propostos por Instituições de Ensino Superior (IES) e desenvolvidos por grupos de 
licenciandos, sob a supervisão de professores da Educação Básica e coordenação de professores das IES, com a finalidade de: a) incentivar a formação de docentes em nível superior para a Educação Básica; b) contribuir para a valorização do magistério; c) elevar a qualidade da formação inicial de professores nos cursos de licenciatura, promovendo a integração entre Ensino Superior e Educação Básica; d) inserir os licenciandos no cotidiano de escolas da rede pública de educação, proporcionando-lhes oportunidades de criação e participação em experiências metodológicas, tecnológicas e práticas docentes de caráter inovador e interdisciplinar que busquem a superação de problemas identificados no processo do ensino e da aprendizagem; e) incentivar escolas públicas de Educação Básica, mobilizando seus professores como conformadores dos futuros docentes e tornando-os protagonistas nos processos de formação inicial para o magistério; f) contribuir para a articulação entre teoria e prática necessárias à formação dos docentes, elevando a qualidade das ações acadêmicas nos cursos de licenciatura; g) contribuir para que os estudantes de licenciatura se insiram na cultura escolar do magistério, por meio da apropriação e da reflexão sobre instrumentos, saberes e peculiaridades do trabalho docente (BRASIL, 2013).

A UNOESC aderiu ao programa do PIBID em 2010 e atua em 48 escolas públicas com subprojetos nas áreas de Pedagogia, Educação Física, Artes Visuais, Música e História. Cada subprojeto atua com cinco acadêmicos bolsistas do respectivo curso em cada escola. O professor supervisor e o coordenador de área auxiliam e acompanham os bolsistas no desenvolvimento de competências docentes e preparação dos acadêmicos para o ingresso na carreira, objetivando dotá-los de postura investigativa e inspirá-los para o uso de novas metodologias e linguagens. O acadêmico vivencia, reflete e entende o que, por que e como planejar ações educacionais numa perspectiva da participação coletiva dos sujeitos.

Este trabalho integra atividades interdisciplinares das diferentes áreas e apoio aos projetos desenvolvidos na escola em que os bolsistas atuam, buscando contemplar discussões e reflexões sobre os processos do ensino e da aprendizagem.

Ao articular a Universidade à escola pública, o programa possibilita aos acadêmicos vivenciar e conhecer experiências do cotidiano escolar, qualificando-os para o 
exercício da profissão de professor. Por sua vez, os professores da rede pública contribuem atuando como co-formadores dos licenciandos. Esta sintonia oportuniza um novo olhar para a formação de professores, distanciando a ideia de que a teoria está na universidade e a prática no espaço escolar. Para as instituições educativas, o PIBID é de suma importância, já que fortalece a integração com a Educação Básica e pode criar espaços de práxis.

Logo, o objetivo do presente estudo foi investigar o Ensino Superior e o PIBID na formação continuada de professores, e na formação inicial dos estudantes que participam do Projeto. O estudo foi desenvolvido por meio de pesquisa qualitativa, de cunho exploratório na metodologia de análise de conteúdo, a qual se deteve, principalmente, na compreensão de três categorias: a) O PIBID enquanto processo de formação inicial e continuada; b) O PIBID e a relação entre teoria e prática; c) O PIBID e o enriquecimento do fazer pedagógico, principalmente no auxílio dos alunos com dificuldades e no trabalho individualizado.

A opção pela pesquisa qualitativa ocorreu em razão de favorecer a compreensão particular daquilo que se estuda, buscando o significado das ações, situações, representações dos indivíduos, enfim, daquilo que pode ser manifestado.

A pesquisa foi desenvolvida em duas escolas públicas da Educação Básica. A amostra foi composta por cinco professores que atuam na Educação Básica (no programa PIBID são denominados supervisores dos acadêmicos bolsistas), sendo quatro do Curso de Pedagogia e um do Curso de Música. Foram envolvidos, ainda, três acadêmicos bolsistas do Curso de Pedagogia e dois do Curso de Música. Também participaram dois coordenadores de Pedagogia e o coordenador do Curso de Música, somando um total de treze sujeitos.

A coleta de dados foi efetuada a partir de entrevistas semiestruturadas com os sujeitos envolvidos na pesquisa. As entrevistas possibilitam a compreensão de sentidos das relações no contexto da pesquisa, como resultado dos processos de interlocução dialógica nas vozes dos pesquisados e do pesquisador, sem os limites rígidos de perguntas e respostas previamente determinadas. 
A intenção do pesquisador é ir além da mera busca de informações; o que deseja é criar um clima de confiabilidade, a fim de que o sujeito entrevistado forneça dados relevantes para a pesquisa. Busca-se a participação ativa e em profundidade dos sujeitos que têm oportunidade de dizer e de refletir. Nessa relação, o contato presencial estabelece uma relação emocional e intelectual. Nesse contexto, Richardson (1999, p. 207) destaca:

\begin{abstract}
A melhor situação para participar na mente de outro ser humano é a interação face a face, pois tem o caráter, inquestionável da proximidade entre as pessoas, que proporciona as melhores possibilidades de penetrar na mente, vida e definição dos indivíduos. Esse tipo de interação entre as pessoas é um elemento fundamental na pesquisa [...]
\end{abstract}

As entrevistas foram realizadas em horário e local agendados com os sujeitos envolvidos. Ocorreram de forma oral e as respostas foram gravadas e transcritas. Vale enfatizar que as entrevistas foram autorizadas pelos sujeitos a partir do Termo de Consentimento Livre e Esclarecido, número de aprovação 51498615.7.0000.5367, Certificado de Apresentação para Apreciação Ética (CAAE).

A fim de preservar a identidade dos envolvidos na pesquisa, assim foram denominados: os acadêmicos de Pedagogia AP1, AP2, consecutivamente; os de música AM1 consecutivamente. Os professores supervisores de Pedagogia como SP1, SP2, consecutivamente, e o professor de música como SM1. Os coordenadores de Pedagogia como $\mathrm{CP} 1$ e $\mathrm{CP} 2$ e o Coordenador de Música como CM. A análise dos dados ocorreu a partir das entrevistas e à luz do referencial teórico.

Elegemos análise de conteúdo, bem como as categorias de análise citadas para interpretar e alinhar o discurso dos acadêmicos, professores e coordenadores participantes da investigação, considerando seus contextos e permitindo entender o significado que o objeto de estudo representa no cotidiano escolar, para cada um deles.

Ao encontro disso, Silva, Gobbi e Simão (2005, p. 70) postulam que: 
A proposta que acompanha a análise de conteúdo se refere a uma decomposição do discurso e identificação de unidades de análise ou grupos de representações para uma categorização dos fenômenos, a partir da qual se torna possível uma reconstrução de significados que apresentem uma compreensão mais aprofundada da interpretação de realidade do grupo estudado.

Por conseguinte, ao analisar os dados da presente pesquisa, articulamos as concepções de diferentes autores com os relatos dos sujeitos envolvidos ao dar-lhes vez e voz, a fim de manifestar suas percepções, bem como contribuir para nossas vivências enquanto professoras e pesquisadoras, como também a possibilidade de ir além do que está posto na escola da Educação Básica.

\section{Vozes de acadêmicos, professores e coordenadores sobre a formação} continuada no PIBID

O Ensino Superior se constitui como o nível mais elevado de ensino, no qual são formados profissionais capazes de atuar conforme sua área de trabalho.

A cada dia mais os avanços tecnológicos e da ciência modificam o cotidiano do homem, mais as relações entre as pessoas se estreitam, possibilitando estar informado o tempo todo sobre tudo o que acontece.

Portanto, o Ensino Superior também necessita de constantes reformulações, pois,

Se é o mercado de trabalho que determina a formação universitária, impondo currículos de curta duração e voltados ao atendimento das necessidades laborais e as características dos empregos do momento, muitos da comunidade acadêmica e científica temem que a universidade perca suas perspectivas de longo prazo e se afaste das referências sociais. (DIAS SOBRINHO, 2005, p. 122)

Assim, repensar a educação também é investir na qualidade dos profissionais formados nas IES, considerando como, quando e o que é efetuado no que diz respeito à 
formação continuada, dos professores que atuam nas escolas ao longo dos anos de sua carreira docente.

É nesse contexto que se insere a formação continuada, baseada na investigação, processo de aprimoramento de técnica, informação e/ou conhecimento. É por meio da formação continuada que os profissionais aprimoram suas ações de trabalho, analisam suas práticas e reveem seu compromisso social com a profissão, atentos aos avanços da ciência e da tecnologia presente.

A Universidade é a instância de formação docente; os Cursos de Licenciatura, prioritariamente, necessitam planejar currículos que atendam à formação inicial e continuada dos profissionais da educação. Para Esteves e Rodrigues (1993, p. 44-45), formação contínua é:

Aquela que tem lugar ao longo da carreira profissional após a aquisição da certificação profissional inicial (a qual só tem lugar após a conclusão da formação em serviço) privilegiando a ideia de que a sua inserção na carreira docente é qualitativamente diferenciada em relação à formação inicial, independentemente do momento e do tempo de serviço docente que o professor já possui quando faz a sua profissionalização, a qual consideramos ainda como uma etapa de formação inicial.

A informação circula de maneira rápida e a educação necessita de professores que saibam produzir conhecimento a partir das inúmeras informações. É necessário ponderar que o aluno, independentemente de seu nível de ensino, precisa ser considerado de maneira íntegra, seja na questão de conhecimento científico, seja na questão afetiva. De acordo com Sousa (2008, p. 25), “muitas políticas públicas investem constantemente na formação continuada dos docentes, pois estes precisam produzir saberes para se transformarem em membros de uma corporação específica, a dos que sabem ensinar”.

Nas universidades, uma alternativa de formação contínua é oportunizada pelo programa do PIBID. As atividades se desenvolvem em escolas públicas de Educação Básica, considerando que a formação acadêmica acontece também na experiência e no envolvimento de ações do ensino e da aprendizagem no campo de trabalho. 
No ano de 2014, a Coordenação de Aperfeiçoamento de Pessoal de Nível Superior (Capes) concedeu 90.247 bolsas de iniciação à docência, abrangendo 283 Instituições de Ensino Superior públicas, privadas e comunitárias e 6.055 escolas públicas, despontando como um dos principais programas de formação inicial e valorização docente (BRASIL, 2014).

No contexto desse programa insere-se a discussão a respeito da distância entre o espaço formativo - a universidade - e o lócus da aplicação dos conhecimentos - a escola pública. Quanto mais distante está o docente em formação do seu contexto de ação, maiores as falsas expectativas a respeito da inserção, maior a possibilidade de frustração e menor a possibilidade de que esse estudante permaneça no ensino público.

Em razão dessa parceria entre a Universidade e as escolas públicas é necessário conhecer as relações que se concretizam nestes espaços e tempos, a fim de compreender a articulação do PIBID com a formação docente inicial e continuada.

\section{O PIBID no processo de formação inicial e continuada}

Assim, para contemplar a primeira categoria de análise, foi relevante considerar a percepção do acadêmico (bolsista), do professor (supervisor) e do coordenador de área, em relação ao PIBID enquanto processo de formação.

Referindo-se à sua experiência no programa PIBID: AP3 assim se manifesta: "Essa articulação do PIBID é fundamental. Temos muita teoria na graduação, mas pouca prática da realidade da sala de aula. Não há articulação entre teoria e prática".

Por sua vez, AP1 menciona: “O PIBID me trouxe o conhecimento na prática. Eu não tinha habilidade para cortar uma flor e hoje eu monto painéis. Tenho mais facilidade em articular meus conhecimentos com a necessidade dos alunos. O PIBID foi um complemento significativo na graduação".

Na mesma esteira, AM1 assinala: "Com o PIBID vou aprendendo como ser professor, como agir com cada um dos alunos, pois são diferentes, tanto na questão 
cognitiva quanto na afetiva. Se nós acadêmicos sentimos que o afetivo influencia na aprendizagem, imagina então, os alunos do Ensino Fundamental”.

Sabemos que a percepção de $\mathrm{AM} 1$ não é considerada pela maioria dos professores, seja o nível de ensino em que atua. Porém, geralmente, tal professor também não é percebido enquanto ser intelectual e emocional. No cotidiano da escola, de maneira geral, ele passa despercebido pelo seu colega, pelos gestores e muitas vezes pelos alunos. É considerado apenas que ele está aí para ensinar. Nesse sentido, Wallon (1975, página?) postula: “Nas relações do processo do ensino e da aprendizagem a afetividade ocupa lugar central. As emoções são a ferramenta principal de interação com os outros e com meio".

As observações dos acadêmicos evidenciam que o conceito de formação acadêmica não pode apenas ser considerado como uma atividade com tempos e espaços determinados e limitados, mas como processo de construção. Construção essa que lhe oportunize articular o conhecimento adquirido no Ensino Superior somado ao contexto da sala de aula na qual o acadêmico atua.

Nesse aspecto, Candau (2011, p. 69) propõe que “o fazer pedagógico (o qual abrange 'o que ensina' e 'como ensina') deve se fazer articulado 'ao para quem' e 'para que', expressando a unidade entre os conteúdos teóricos e instrumentais”.

Observamos, então, que a educação se efetiva nos contextos e em seus entornos, considerando professor, aluno, conteúdo, objetivos, estratégias, métodos e atividades.

A inserção nas escolas básicas, em processo de aprender a ser docente orientada por um profissional com experiência, de maneira contínua, é uma alternativa de formação profissional nas interações da experienciação nas Licenciaturas.

Consoante com Estrela (apud FERREIRA, 2007, p. 54),

[...] se quisermos contribuir para a mudança dos professores e das escolas, teremos de partir das suas culturas, o que aliás será mais coerente com a defesa que se faz, em termos teóricos, de "dar vez e voz" aos professores e com a importância atribuída aos contextos para a compreensão da acção formativa ou educativa. 
Nessa circularidade, AP4 declara: "Dedico mais tempo para estudos e planejamento, pois preciso estar preparada para atender os alunos. Porém essa experiência está sendo significativa. Todo planejamento do estágio, de organização de conteúdo aprendi no PIBID, muito mais que na faculdade". Segundo a aluna, o programa representa uma oportunidade singular de formação profissional, ao possibilitar vivenciar situações pedagógicas.

Referindo-se sobre o desempenho dos acadêmicos na graduação, CM salienta:

Percebo quem é acadêmico na universidade. Eles conseguem entender a articulação entre a teoria e a prática. Percebem, também, que é necessário leitura para o planejamento de suas aulas, como também a importância de articular o lúdico em suas atividades de ensino, envolvendo as diferentes disciplinas.

Da mesma maneira, CP2 destaca: "todas as bolsistas do PIBID têm noção de como é o funcionamento de uma escola. Se destacam entre as demais acadêmicas do curso de Pedagogia".

A formação do professor depende sim da formação inicial, porém esta precisa ser articulada na experiência, na discussão e no envolvimento em situações do ensino e da aprendizagem. Segundo depoimento dos coordenadores, o programa PIBID se evidencia como uma estratégia eficiente na formação do professor ligada ao ensino e à aprendizagem na Educação Básica. Os acadêmicos interagem na sala de aula da graduação, com exemplos da prática. Isso tudo requer que eles busquem mais leituras e diferentes metodologias de ensino.

Quanto à importância e necessidade de o profissional docente em formação vivenciar os espaços de atuação, Nóvoa (2009, p. 19) alerta:

É preciso passar a formação de professores para dentro da profissão [...], não haverá nenhuma mudança significativa se a comunidade de 
formadores e de professores não se tornarem mais permeáveis e imbricadas. [...] Refletir coletivamente sobre seu trabalho, mobilizando conhecimentos, vontades e competências, através do estudo aprofundado de cada caso, sobretudo nos casos de insucesso escolar; análise coletiva das práticas pedagógicas; obstinação e persistência profissional para responder às necessidades e anseios dos alunos; compromisso social e vontade de mudança [...], propostas que só fazem sentido se construídas dentro da profissão, se forem apropriadas a partir de uma reflexão dos professores sobre o próprio trabalho.

O entendimento do contexto em que acontece a formação docente nos leva a compreender como as ações executadas auxiliam no desenvolvimento dos saberes docentes. Quais as necessidades, como se evidenciam e de que forma influenciam na intervenção pedagógica em sala de aula.

Nesse sentido, AP2 relata: "O PIBID me proporcionou superar minha timidez perante os alunos e professores. Percebi que se não tiver voz e não conseguir mostrar a minha opinião, eu não vou ser uma boa professora". A acadêmica aponta que os bolsistas se capacitam para a reflexão responsável sobre as fragilidades e as potencialidades dos processos de educação, a partir da inserção nas escolas.

Já AP4 observa a articulação entre teoria e prática que o programa vem proporcionando a ela: “Quando entrei no Curso, eu batalhei pelo PIBID justamente porque eu queria esse envolvimento. Tinha receio em ir para a sala de aula. A professora contribuiu, passei a integrar o que eu via na universidade com a prática”. Do mesmo modo, CP1 certifica: “o PIBID contribui de maneira significativa na formação continuada entre a UNOESC e Educação Básica. As vivências experienciadas proporcionam aos acadêmicos conhecer a realidade escolar, a fim de compreender e articular a teoria com a prática".

\section{O PIBID e a relação teoria e prática}

Enquanto professores das licenciaturas, precisamos estar atentos ao que mencionam $\mathrm{AP}_{4}$ e $\mathrm{CP} 1$, no parágrafo anterior. A relação teoria e prática é muito referendada nos cursos de licenciatura, por parte dos acadêmicos, pois "existe uma 
grande distância entre os conhecimentos adquiridos durante o curso e o que o acadêmico encontra na prática, sendo necessário uma revisão daquilo que é ensinado" (CANDAU, 2011, p. 56).

Consideramos, nesse contexto, que o PIBID pode possibilitar a articulação entre a universidade, o acadêmico e a Educação Básica. Com o apoio dos professores, os acadêmicos se apropriam da prática pedagógica e potencializam os estudos teóricos nas intervenções realizadas nas escolas.

Em relação à oportunidade de vivenciar essas experiências como professora, AM2 declara:

A partir do PIBID observei que o conteúdo da escola tem relação com o contexto dos alunos. Por exemplo: alimentação. Eu apresentava figuras de comida e pedia para as crianças se aquela comida era saudável ou não. Elas respondiam e iam refletindo sobre como se alimentavam. Os alunos brigavam muito no recreio. Usamos a música, em diferentes brincadeiras, alteramos tal realidade.

Na percepção de AM2 foi importante articular o conteúdo elegido pela escola e a teoria universitária, com a realidade dos alunos. A reflexão proporcionada aos alunos fez com que revissem sua maneira de se alimentar. Do mesmo modo, observa-se que a formação inicial oportuniza diferentes conhecimentos teóricos, porém esses precisam ser articulados ao contexto vivenciado pelos acadêmicos.

Nessa direção, Tardif e Lessard (2008, p. 133) enfatizam:

A forma universitária de ensino não poderia garantir, sem profundas adaptações, uma formação profissional de qualidade. Não é possível construir competências, limitando-se a distribuir saberes e a confiar em alguns estágios de fim de estudos para assegurar a ligação entre a teoria e prática.

Os projetos do PIBID organizam a formação acadêmica em movimentos de alternância porque possibilitam integrar teoria e prática em processos de vivência e 
parcerias no contexto de atuação profissional, nas escolas públicas de Educação Básica. AP3 assegura: "aprendemos na graduação a importância da socialização e da interlocução, mas só compreendemos isso no cotidiano da escola, com a ajuda da supervisora".

Da mesma maneira, SP3 assinala: "Aprendi com as acadêmicas, muita teoria, a parte científica que, às vezes, deixamos de lado pela praticidade da sala de aula. E o que eu repassei foi a minha experiência em sala de aula. Era uma troca constante". Ao ser questionada em relação à troca de experiência e conhecimento entre a acadêmica e sua professora, SP5 estabelece:

Ao mesmo tempo que contribui na prática das acadêmicas, elas proporcionaram que eu voltasse à teoria. Por exemplo, Vygotsky quando aborda que conhecimento implica ação compartilhada nas interações. A importância do outro na aprendizagem. Também observa que é preciso considerar o contexto do aluno e articulá-lo ao conteúdo desenvolvido na escola. A questão da importância de considerar que o aluno não é só intelectual, mas também afetivo mencionado por Wallon. Considero que isso é uma formação continuada.

A formação continuada precisa ser entendida como permanente, conforme as necessidades sentidas pelos professores seja no sentido teórico ou prático. Considerar também que ela precisa acontecer no cotidiano escolar durante os processos do ensino e da aprendizagem, exigindo, assim, estudo, planejamento, reflexão e ação. Segundo Ferreira (2007, p. 19-20),

A formação continuada é uma realidade no panorama educacional brasileiro e mundial, não só como uma exigência que se faz devido aos avanços da ciência e da tecnologia que se processam nas últimas décadas, mas como uma nova categoria que passou a existir no mercado da formação contínua e que, por isso, necessita ser representada cotidianamente no sentido de melhor atender à legítima e digna formação humana. 
Diante disso, SP4 relatou: “Na sala de aula, eu observava a prática delas (acadêmicas) e percebia que precisava aprender mais, principalmente nas ações lúdicas, nas quais os alunos desenvolviam com criatividade as atividades das diferentes disciplinas a partir do concreto, jogos e brincadeiras".

Vale ressaltar que enquanto as acadêmicas revelam a experiência na escola como formação na prática, as professoras das escolas enfatizam a formação teórica que elas estão revisitando a partir dos estudos realizados entre elas. Consideramos relevante destacar aqui Pimenta (2002, p. 33), quando relata sua experiência com professores da Educação Básica,

Ao expor a importância da análise das práticas dos professores em seus contextos, colocavam em evidência a escola como espaço institucional de práticas coletivas. A compreensão dos processos de constituição do saber fazer docente no local de trabalho abria para o estudo da escola nos cursos de formação e para novas possibilidades de se articular a formação inicial e continuada.

Assim, a universidade precisa ser agente de formação continuada dos professores. Entender que o processo de educação precisa ser continuamente repensado. Planejar a educação significa trazer para a sala de aula alternativas que possibilitem o desenvolvimento dos acadêmicos enquanto profissionais da educação. A universidade precisa contribuir para que tal profissional perceba o que, como e para quem ensinar. Que ele observe as diferenças em sala de aula e como pode contribuir de maneira efetiva na aprendizagem dos alunos, seja para a área que for. Isso vai ao encontro do relato de AP2: "usamos jogos na matemática com o objetivo de estudar unidade, dezena e centena. Os alunos entenderam diferentes conceitos matemáticos. Observaram cores, tamanhos e quantidades".

AP1 destaca: “fizemos vários jogos baseados na Bacia Hidrográfica do Rio do Peixe: efluente, mata ciliar. Focamos a parte da Geografia, da Matemática e da Língua Portuguesa por meio da oralidade e sinônimo das palavras. Em Ciências, a parte orgânica, animais e plantas". 
Ao referir-se aos jogos, Fernandes et al. (1995. p. 2) enfatizam:

[...] os jogos podem ser empregados em uma variedade de propósitos dentro do contexto de aprendizado. Um dos usos básicos e muito importantes é a possibilidade de construir-se a autoconfiança. Outro é o incremento da motivação. [...] um método eficaz que possibilita uma prática significativa daquilo que está sendo aprendido. Até mesmo o mais simplório dos jogos pode ser empregado para proporcionar informações factuais e praticar habilidades, conferindo destreza e competência.

É preciso que o professor esteja atento aos jogos como auxílio para aprendizagem tornando-o material de apoio e não peça principal do conhecimento, observando os objetivos que aquela atividade trará para os alunos e se essa forma pedagógica contribuirá para o ensino e a aprendizagem.

\title{
O PIBID e o enriquecimento do fazer pedagógico no auxílio aos alunos com
}

\section{dificuldades}

É necessário que os profissionais da educação estejam preparados para atuar em sala de aula, a fim de que o aprendizado seja efetivado mesmo diante das adversidades que a cultura implica. Portanto,

\begin{abstract}
A preocupação pela "eficácia" da formação inicial e continuada aparece normalmente ligada às questões dos modelos e estratégias utilizadas, da sua adaptabilidade a evolução do papel do professor e educador e a diversidade dos contextos em que a ação educativa vai se desenvolver, da preparação para a investigação e para a inovação. (NÓVOA, 2000, p. 114)
\end{abstract}

A formação contínua de docentes não se limita a cursos frequentados, inúmeros diplomas ou ao método de formação, e abrange a atividade prática do profissional, sua capacidade de regeneração, mudança e criatividade. 
Os programas de iniciação e formação à docência possibilitam que os acadêmicos tenham a base fundamental para iniciar a docência com segurança, uma vez que "os saberes da experiência, os saberes do conhecimento e os saberes pedagógicos são de fundamental importância para o exercício da docência, de forma que se evite deixar o professor à deriva da própria sorte" (PIMENTA, 2002, p. 54).

É importante ressaltar que as universidades formadoras de docentes têm responsabilidades significativas na carreira de seus acadêmicos. Nas licenciaturas, o PIBID pode contribuir na formação significativa, a fim de que o acadêmico possa refletir a respeito do conhecimento científico articulado ao cotidiano da sala de aula.

A educação e as formas de educar vêm se modificando e têm exigido do docente muito mais do que conhecimento teórico. Na concepção de Nóvoa (2009, p. 240), “avançou-se muito do ponto de vista da análise teórica, mas se avançou muito pouco nas práticas da formação de professores".

Consideramos que a Universidade tem o papel preponderante de articular os conhecimentos teóricos à execução prática, principalmente no que se refere às licenciaturas. Nesse sentido, o PIBID oportuniza essas interlocuções e, consequentemente, as vivências na Educação Básica.

Em relação à contribuição do PIBID nas atividades de reforço, que teve como objetivo auxiliar alunos com dificuldades, AP1 declara: “Com o reforço nós trabalhávamos a dificuldade de cada um. Com auxílio da professora, desenvolvíamos atividades específicas. Na matemática, foi utilizado material dourado para estudar unidade, dezena e centena. Os alunos, a partir do concreto, assimilaram o conteúdo". Nesse sentido, AP3 salienta: "Nas aulas de reforço damos ênfase às dificuldades dos alunos nos diferentes conteúdos do primeiro ano. Percebemos que a alfabetização poderia ser trabalhada de maneira interdisciplinar. Trabalhamos Língua Portuguesa, Matemática e Geografia articuladas ao contexto vivenciado por eles".

SP2 registra: "Com o reforço os alunos tiveram um avanço significativo nos diferentes conteúdos. Trabalhávamos as dificuldades individualmente". SP1 valoriza a brincadeira na operação matemática. "Com um aluno que tinha muita dificuldade na 
matemática, usamos a brincadeira com bolachas. Elas tinham símbolos numéricos.

Desenvolvemos a adição, a subtração e multiplicação. Observamos que, a partir da brincadeira, adquiriram mais segurança nas operações matemáticas."

Na utilização de jogos para aulas de reforço, AP4 relata:

Para trabalhar a dificuldade com a matemática nós brincamos no pátio com a ordenação dos números, a ordem crescente e decrescente. Desenhei no círculo uma bola e coloquei os números dentro. Eles tinham que ir pulando. Eu pedia que eles pulassem dentro dos quadrados de forma crescente. Mas, professora, o que é crescente? Eu respondi: o que você entende por crescente? O aluno respondeu: é uma coisa. Muito bem! É como se fosse 1, 2, 3, 4 e vai crescendo? Ao final, os alunos compreenderam os conceitos de crescente e decrescente, de maneira efetiva.

Os jogos estão presentes no cotidiano dos alunos, estão além de uma brincadeira.

Têm fundamental importância nas relações do ensino e da aprendizagem para construção de novos conhecimentos cognitivos, como na formação moral, afetiva e social. Piaget (1976, p. 160) registra:

O jogo é, portanto, sob as suas formas essenciais de exercício sensóriomotor e de simbolismo, uma assimilação do real à atividade própria, fornecendo a esta seu alimento necessário e transformando o real em função das necessidades múltiplas do eu. Por isso, os métodos ativos de educação das crianças exigem que se forneça às crianças um material conveniente, a fim de que, jogando elas cheguem a assimilar as realidades intelectuais que, sem isso, permanecem exteriores à inteligência infantil.

A partir dos relatos, observamos, também, a importância de a escola planejar e contemplar o estudo individualizado, considerando as diferenças e especificidades existentes nas salas de aula. Pensar a intervenção pedagógica significa conhecer e respeitar essas diferenças. Por essas razões, o professor necessita se aperfeiçoar para atender tais demandas, uma vez que, 
[...] o único educador capaz de formar novas reações no organismo é a própria experiência [...]. Toda tese teórica é comprovada ou verificada mediante a prática, e sua veracidade só se estabelece quando a prática construída sobre aquela se justifica. É o mesmo que acontece com a aprendizagem da criança a teoria ajuda a entender os conteúdos, mas é na prática que o aluno irá compreender. (VYGOTSKY, 2003, p. 75)

Enquanto professoras, precisamos contribuir para o desenvolvimento de cidadãos com visão crítica e reflexiva da sua realidade e de mundo; ser capazes de tomar decisões sobre o futuro; ter consciência política e social das questões que envolvem o contexto vivenciado.

A articulação entre os professores da Educação Básica e os acadêmicos pode contribuir significativamente no desenvolvimento do ensino e da aprendizagem na sala de aula da Educação Básica. A interlocução de diferentes saberes docentes media a intervenção pedagógica de maneira efetiva, de acordo com os envolvidos na presente pesquisa.

\section{Considerações finais}

O presente estudo objetivou investigar o Ensino Superior e o Programa Institucional de Bolsa de Iniciação à Docência (PIBID) na formação continuada na Educação. Para sua execução, desenvolvemos uma pesquisa qualitativa com a participação de acadêmicos, professores e coordenadores dos cursos de Pedagogia e Música, cursos estes integrantes do PIBID.

Como categorias de análise, buscamos alinhar as vozes dos sujeitos em três categorias, examinando-as à luz da teoria. Dessa forma, com relação à primeira categoria, que buscou analisar o PIBID enquanto ferramenta no processo de formação inicial e continuada, os dados da pesquisa evidenciam que o Programa possibilita a aproximação das discussões acadêmicas com as práticas realizadas no contexto das escolas. Os acadêmicos envolvidos relataram que o programa oportunizou vivenciar o conhecimento 
teórico estudado e socializado no Ensino Superior, tanto no planejamento das intervenções pedagógicas quanto na compreensão das formas de organização da escola. Os achados, portanto, caminham ao encontro dos ensinamentos de Ferreira (2007) e Zabalza (2004), quando os autores reforçam que a formação inicial, bem como a formação continuada devem ser de qualidade.

No que concerne à segunda categoria, o PIBID, na relação entre teoria e prática, os participantes da pesquisa perceberam que o aperfeiçoamento das práticas fundamentadas em teorias clássicas e contemporâneas permite construir e avaliar diferentes possibilidades na formação docente, as quais contribuem significativamente na intervenção da sala de aula, na Educação Básica. Os relatos dos sujeitos da pesquisa se colocam consoantes aos autores estudados, principalmente Tardif e Lessard (2008), a ligação entre teoria e prática na formação de professores não pode estar condicionada somente aos estágios de final de curso. Na mesma esteira, caminha o entendimento de Nóvoa (2009) e Candau (2011), os quais relatam que a distância entre a teoria que se aprende no curso e a prática deve ser subsumida com a vivência em espaços de atuação pedagógica.

A articulação entre o Ensino Superior, o PIBID e a prática na sala de aula, portanto, na voz dos acadêmicos, dos professores e Coordenadores oportuniza compreender e aprender o exercício da profissão, nas relações entre teoria e prática e no planejamento e execução das ações pedagógicas.

Por fim, a terceira categoria de análise buscou ponderar a importância do PIBID no enriquecimento do fazer pedagógico, principalmente no auxílio aos alunos com dificuldades e no trabalho individualizado. A respeito deste assunto, os entrevistados relatam que tiveram a oportunidade de refletir sobre a própria prática em relação ao rendimento pedagógico no trabalho com os alunos que apresentam maiores dificuldades, sendo que observaram que estas complicações podem ser fruto da organização escolar ou do próprio sistema de ensino do professor. Por isso, enfatizam a necessidade de investigação e reflexão centradas nos sujeitos e nos processos de aprendizagens. 
Esse movimento pedagógico do PIBID rompe com paradigmas ultrapassados da formação de professores que valorizam somente a prática ou apenas a teoria. Na percepção dos acadêmicos, foi-lhes oportunizada a compreensão do fazer docente, processo complexo que necessita ser percebido como exercício permanente de análise, estudo e reflexão.

Destacam também como importantes, os espaços coletivos de convivência acadêmica e profissional, solidariedade de pensamento e ação, somas constantes de experiências docentes e de gestão escolar. Entrelaçados que possibilitaram intervenções educativas muito mais sólidas e conscientes.

Compreendemos que este estudo não se encerra aqui, pois a pesquisa precisa ter sequência de investigação no que se refere à percepção das fragilidades da profissão docente; mais possibilidades de parceria entre escolas públicas e Universidade; aperfeiçoamento das práticas fundamentadas em teorias; entendimento da complexidade e importância do comprometimento para com a profissão.

Consideramos ainda que, na continuidade da pesquisa, será relevante incluir estudos sobre o Programa desenvolvido em outras universidades para análise comparativa ainda que o mesmo esteja sofrendo de fortes cortes econômicos devido a ajustes fiscais do atual governo'.

\section{Referências}

BRASIL. Relatório de Gestão DEB 2009/2014. Brasília, DF, 2014, v. 1. Disponível em: <http://www.capes.gov.br/images/stories/download/legislacao/Portaria_096_18jul13_Apr ovaRegulamentoPIBID.pdf>. Acesso em: 20 out. 2015.

BRASIL. Portaria n. 096, de 18 de julho de 2013. Regulamento do Programa Institucional de Bolsa de Iniciação à Docência PIBID. Brasília: MEC/Capes, 2013. Disponível em: <http://www.capes.gov.br>. Acesso em: 20 out. 2015.

\footnotetext{
${ }^{1}$ No início do ano de 2016, o Programa foi ameaçado de extinção, mas depois o MEC voltou atrás. Ainda assim, profundos cortes foram realizados. Mais informações em: http://www.anped.org.br/news/secretario-do-mec-anuncia-revogacao-do-oficio-da-capes-sobre-cortes-nopibid. Acesso em 18 abril de 2017.
} 
BRASIL. Lei de Diretrizes e Bases da Educação Nacional: Lei n. 9.394, de 20 de dezembro de 1996. Brasília: MEC, 1996. Disponível em:

<http://portal.mec.gov.br/arquivos/pdf/ldb.pdf>. Acesso em: 20 out. 2015.

CANDAU, Vera Maria (Org.). Rumo a uma nova didática. 21. ed. Petrópolis: Vozes, 2011.

DIAS SOBRINHO, José. Dilemas da educação superior sociedade do conhecimento ou economia do conhecimento? São Paulo: Casa do Psicólogo, 2005.

ESTEVES, Manuela; RODRIGUES, Ângela. A análise de necessidades na formação de professores. Porto: Porto Editora, 1993.

FERNANDES, Lúcio Dutra et al. Jogos no computador e a formação derecursos humanos na indústria. In: SIMPÓSIO BRASILEIRO DE INFORMÁTICA NA EDUCAÇÃO, 6., 1995, Florianópolis. Anais... Florianópolis: SBC-UFSC, 1995.

FERREIRA, Naura Syria Carapeto. Formação continuada e gestão da educação. 3. ed. São Paulo: Cortez, 2007.

NÓVOA, António. Professores imagens do presente. Lisboa: Relgráfica artes gráficas. Benedita, 2009.

NÓVOA, Antonio (Org.). Vidas de professores. Porto: Ed. Porto, 2000.

PIAGET, Jean. Psicologia e pedagogia. Tradução Dirceu Accioly Lindoso e Rosa Maria Ribeiro da Silva. Rio de Janeiro: Forense Universitária, 1976.

PIMENTA, Selma Garrido. Professor reflexivo no Brasil: gênese e crítica de um conceito. 2. ed. São Paulo: Cortez, 2002.

RICHARDSON, Roberto Jarry. Pesquisa social: métodos e técnicas. 3. ed. rev. e ampl. São Paulo: Atlas, 1999.

SILVA, Cristiane Rocha; GOBBI, Beatriz Christo; SIMÃO, Ana Adalgisa. O uso da análise de conteúdo como uma ferramenta para a pesquisa Qualitativa: descrição e aplicação do método. Organizações Rurais \& Agroindustriais, Universidade Federal de Lavras, v. 7, n. 1, p. 70-81, 2005.

SOUSA, Maria Goreti da Silva. A formação continuada e suas contribuições para a profissionalização de professores dos anos iniciais do ensino fundamental de Teresina- 
Pi: revelações a partir de histórias de vida. 2008, 130 f. Dissertação (Mestrado em Educação) - Universidade Federal de Piauí, Piauí, 2008.

TARDIF, Maurice; LESSARD, Claude. O Ofício de professor: histórias, perspectivas e desafios nacionais. Tradução de Lucy Magalhães. 2. ed. Petrópolis: Vozes, 2008.

VYGOTSKY, Liev Semionovich. Psicologia pedagógica. Porto Alegre: Artmed, 2003.

WALLON, Henri. Psicologia e educação na infância. Tradução Ana Rabaça. Lisboa: Editorial Estampa, 1975.

ZABALZA, Miguel Angel. O Ensino universitário: seu cenário e seus protagonistas. Porto Alegre: Artmed, 2004.

Recebido em: 20/07/2016

Aprovado em: 14/05/2017

Universidade do Estado de Santa Catarina - UDESC

Centro de Ciências Humanas e da Educação - FAED

Revista PerCursos

Volume 18 - Número 36 - Ano 2017 revistapercursos@gmail.com 